\title{
ASSESSING SOCIAL PERCEPTIONS OF EMERGING POLLUTANTS IN SOUTH-EAST SPAIN
}

\author{
MARIA DE LOS ANGELES BERNAL-ROMERO DEL HOMBRE BUENO ${ }^{1}$, PABLO AZNAR-CRESPO ${ }^{1,2}$, \\ ANTONIO JODAR-ABELLAN ${ }^{1}$, JOAQUÍN MELGAREJO MORENO ${ }^{1}$ \& DANIEL PRATS ${ }^{1}$ \\ ${ }^{1}$ University Institute of Water and Environmental Sciences, University of Alicante, Spain \\ ${ }^{2}$ Department of Sociology, University of Alicante, Spain
}

\begin{abstract}
EMPORE project, co-funded by LIFE Programme (LIFE15 ENV/ES/000598), aims to demonstrate an innovative, cost-efficient and highly replicable technology for the removal of Emerging Pollutants (EPs) from European Waste Water Treatment Plants (WWTPs). In action, C2, a set of indicators to monitor the socio-economic impact of EPs removal, was developed. Framed in this action, a robust assessment of the social perception of these contaminants was performed in the South-East Spain, where the use of reclaimed water is widespread due to the structural water scarcity. An expert consultation by means of a survey technique was held from November to December of 2018 with a sample size of 114 cases. The survey focused on regulation, risk perception, technologies and socioeconomic impact. A descriptive analysis of 19 variables was carried out. In general, the results suggest that the presence of EPs can be a significant risk and destabilization factor in the reuse of wastewaters. The impact of new regulations concerning EPs awakes uncertainty among water experts. Aspects such as the price of water free of EPs, treatment costs or the potential of different technologies to remove these compounds are sources of ambiguity. Nevertheless, experts believe new regulations on EPs will positively influence public health, social confidence or environmental sustainability, among others. It highlights that experts agree that the future of the reuse of wastewater passes through the combination of technologies. These findings provide water planning policy makers with very useful information in the water resources management of the South-East Spain because recent European laws can set new limits of emerging pollutants in waters.

Keywords: emerging pollutants, social perception, descriptive statistical analysis, South-East Spain, water reuse.
\end{abstract}

\section{INTRODUCTION}

The implementation of the Water Framework Directive [1] raises a number of shared technical challenges for the Member States. The aim to reach good ecological status in every water body in Europe is far to be reached. Within this context, emerging contaminants (EPs) is one of the key topics to be addressed in the following years.

Directive [2] (article 26) defines EPs as "pollutants currently not included in routine monitoring programmes at Union level but which could pose a significant risk requiring regulation, depending upon their potential ecotoxicological and toxicological effects and on their levels in the aquatic environment". This term includes a wide variety of compounds, such as pharmaceutical products, flame retardants, personal care products and pesticides, among others.

The main objective of urban wastewater treatment plants (WWTPs) according to the Urban Waste Water Treatment Directive [3] and its extension Directive [4] is to remove suspended solids, organic matter, and, in sensitive areas, nutrients. However, many EPs are resistant to conventional treatments and are not removed neither altered in the water line and finally reach the aquatic media, concerning fact, especially when treated water is reuse.

Water reuse is an accepted practice in several European countries, especially in Spain, where the risks of water scarcity have enhanced the reuse of treated wastewater for agricultural, industrial and urban uses. Reuse of water for agricultural activities is also very 
widespread in southern European countries, although it must also be highlighted that water reuse in these countries is also driven by tourism (BIO Deloitte [5]).

Water scarcity is especially accused in the South-East Spain, region where the reuse of treated water has been widespread to meet water needs for agriculture and tourism, especially in Murcia, Alicante and Almería. There are factors, such as quality, price and availability that may influence the social perception of the reuse of treated waters.

The project LIFE-EMPORE "Development of an efficient and sustainable methodology for EPs removal in WWTPs" (EMPORE-LIFE15 ENV/ES/000598) aims to demonstrate an innovative, cost-efficient and highly replicable technology for the removal of EPs from European WWTPs. The project is due to last 36 months, from September 2016 to August 2019, and its total budget is 1,783,824 €. The participants are: Laboratorios Tecnológicos de Levante S.L., IHE Delft, Entidad Pública de Saneamiento de Aguas Residuales de la Comunidad Valenciana (EPSAR), University of Alicante, Technology Institute on MetalProcessing, Wood, Furniture and related industries (AIDIMME), and CONSOMAR S.A.

The EMPORE project includes the design, construction and operation of a pilot plant that combines a set of technologies (conventional filtration, membranes filtration, advanced oxidation processes and electrochemical processes) to improve the quality of the secondary effluents of WWTPs regarding EPs. The demonstration is carried out in Benidorm (Alicante) and the developed technology will potentially be replicated and used throughout other places of the European Union with similar particularities (presence of EPs and water needs for reuse). Among other objectives, the project EMPORE aims to assess the socio-economic impact of the implementation of the demonstration plant in the local economy and also in other European regions with similar pollution problems. This article focuses on assessing the social perception of EPs in the South-East of Spain, region where the demonstration plant is operated.

\section{STUDY AREA}

The present study was developed during November and December of 2018. Most surveys were realised in the "XIV Technical Symposium on Water Treatment and Purification (Jornadas ESAMUR)" celebrated in the Lorca municipality (province of Murcia, Spain) from 21st to 22nd November 2018 (www.jornadasesamur.com/). This municipality belongs to the Segura river basin district (SE Spain) which presents semiarid climate with irregular and scarce rainfalls (average precipitations of $374 \mathrm{~mm} /$ year, showing clear differences from NW mountain areas, around $1000 \mathrm{~mm} /$ year, to coastal areas with less than $300 \mathrm{~mm} /$ year), high annual average temperatures $\left(18-10^{\circ} \mathrm{C}\right)$, and a large number of hours of sun that generate high potential evapotranspiration rates (average ETP of $993 \mathrm{~mm} / \mathrm{year}$ ) and real evapotranspiration rates (average ETR of $335 \mathrm{~mm} /$ year). Detail information can be found in CHS [6], Gomariz-Castillo et al. [7] and Ruíz-Álvarez et al. [8].

Due to the mentioned climate features, irrigated agriculture developed highly in these areas specially since the seventy-eighty of the last century (alongside the start of the TajoSegura interbasin transfer) and, nowadays, constitutes great water demands together with high water necessities required from the industrial zones and the extend and densely populated urban areas identified in the south-eastern Spain. In particular, the Segura river basin district showed, in 2015 , a total water demand of $1762.1 \mathrm{hm}^{3} /$ year, which $86.2 \%$ corresponded to agricultural water demands, $10.8 \%$ to urban demands, $1.7 \%$ to environmental demands, $0.7 \%$ to industrial demands do not dependent of urban supply networks, and finally $0.6 \%$ to irrigate golf courses (CHS [6]; Albaladejo-García et al. [9]; Grindlay-Moreno and Lizárraga-Mollinedo [10]). As a result of the recognized instability among scarce water inputs and great water demands, currently the Segura river basin district 
presents the highest water resources shortage of Europe (Custodio et al. [11]; MelgarejoMoreno et al. [12]), with several problems of aquifers overexploitation (227 hm 3 year estimated in 2015 by CHS [6], political issues related with interbasin transfers from other watersheds (Molina-Giménez and Melgarejo-Moreno [13]), great rates of desalinated water and reused wastewaters (from desalination: $158 \mathrm{hm}^{3} /$ year to supply agricultural and urban uses; from reused wastewaters: around $78 \mathrm{hm}^{3} /$ year), etc., all of them as measurements to supply the large identified water demands (CHS [6]). Therefore, assessing the social perception of emerging pollutants results especially relevant in areas, as the South-East Spain, where the use of reclaimed water is widespread due to the identified water scarcity. This particular situation has produced that, currently, the SE Spain depicts one of the highest desalinated and wastewater reused rates in the world in terms of production $\left(\mathrm{m}^{3} /\right.$ day), alongside the developed technology and energy consumption $\left(\mathrm{kW}-\mathrm{h} / \mathrm{m}^{3}\right)$ as can be found in Zarzo and Prats [14] and Prats-Rico [15].

Fig. 1 depicts the Lorca municipality in the context of the Segura river basin district, together with the autonomous communities of the surveyed experts.

\section{METHODOLOGY}

An extensive review of the specialized literature was conducted (information not supply), consulting publications about water reuse, water resources management and different aspects of EPs (regulations, social perception, treatment technologies...). The information was useful to define the three basic aspects of this research: i) the conceptual gaps in EPs; ii) the scope and potential topics of the study; and iii) the profile of the experts to consult.

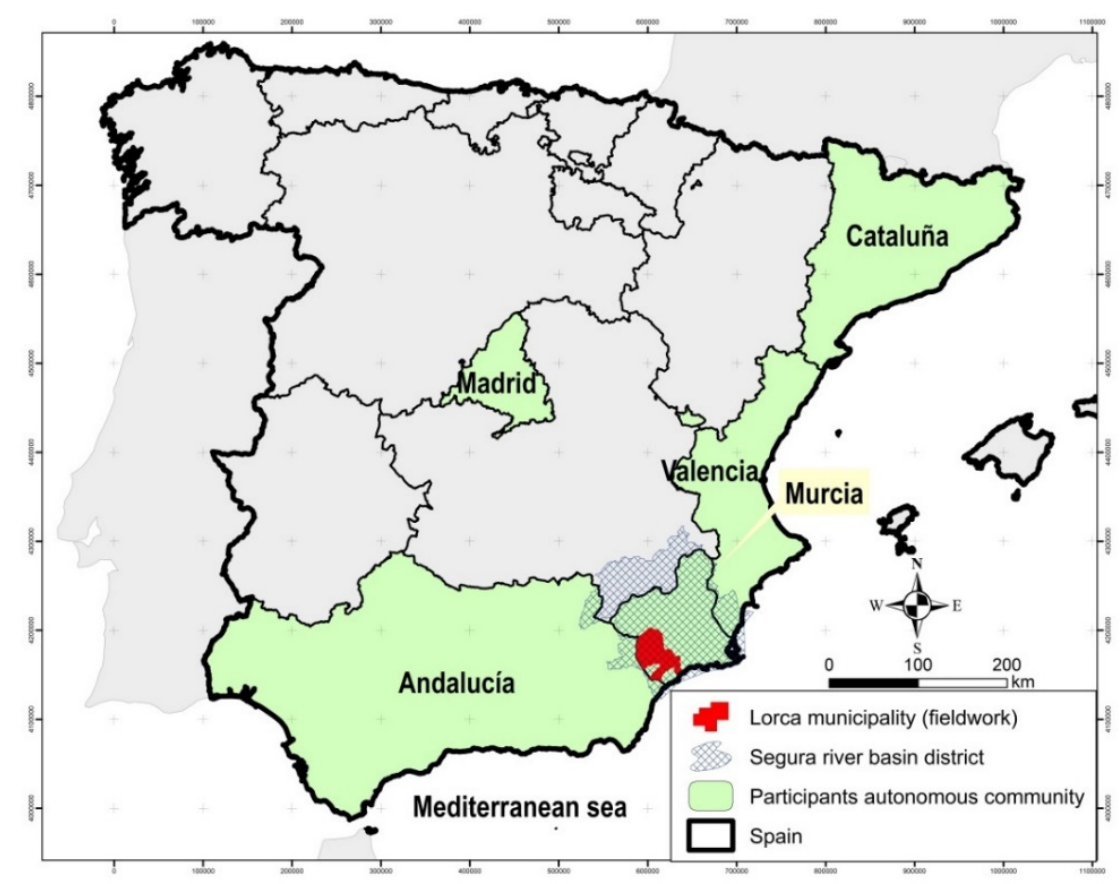

Figure 1: Study area showing the Lorca municipality in the context of the Segura river basin district (SE Spain) and the autonomous communities of the surveyed experts. 
The information to assess the social perception of EPs was obtained through an expert consultation using the survey as a technique of data collection. The questionnaire consisted of three main thematic blocks: i) general aspects; ii) technological aspects; and iii) aspects of social, economic and environmental impact. Due to the scarce specialized literature on perception issues linked to EPs, a generalist approach was implemented to gather information on this topic.

The fieldwork consisted in the realization of face-to-face and individual structured interviews (survey). The survey took place in Lorca municipality from 21 st to 22nd November 2018 during the "XIV Technical Symposium on Water Treatment and Purification (Jornadas ESAMUR)". This congress gathered more than 300 experts in the field of sanitation and wastewater treatment. Due to the geographical proximity, this congress recruited many experts from the provinces of Murcia and Valencia. These regions of the South-Eastern of Spain present the highest levels of water reuse and desalination of this country, and of the greatest of Europe, as a consequence of the identified water deficit (Custodio et al. [11]; Melgarejo-Moreno et al. [12]). Thus, although the statistical stratification of sample was not an objective, a significant number of cases from the regions most linked to water reuse and more potentially affected by EPs was managed. Altogether, 114 case studies were accomplished. This sample size was sufficient to satisfy the requirements of the nonparametric study. Once the primary data was obtained, the processing of data was carried out through the statistical software SPSS [16]. Fig. 2 represents the general methodological diagram achieved in this study.

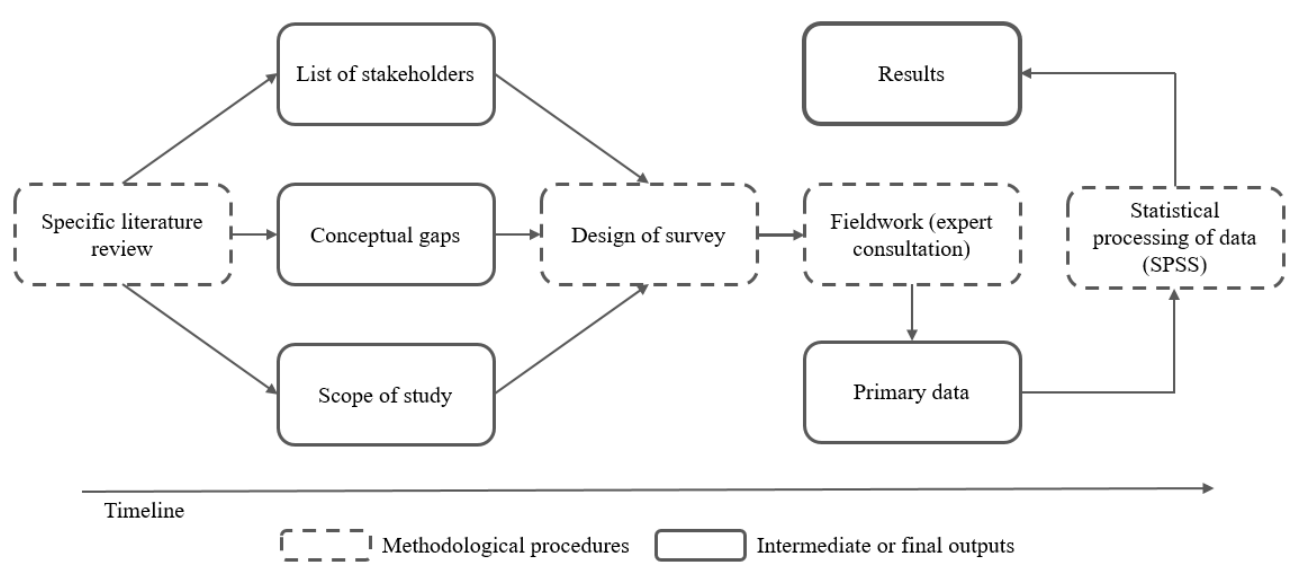

Figure 2: Methodological process of the present study.

The nature of this research is descriptive-exploratory, since it intends to constitute a preliminary approximation to this unknown field of study. In addition, this study does not pursue statistical extrapolation, since its objective, instead of being statistical inference, is the non-parametric exploration of the phenomenon. Therefore, the methodology of the study was the expert consultation and the technique selected to obtain the primary information was the structured interview through a questionnaire (survey). 


\section{RESULTS AND DISCUSSION}

Results obtained in the present study are involved in the three chief sections of the designed survey:

\subsection{General aspects}

One of the aims of this sub-section was to analyse the risk perception that experts have about the future of the reuse of treated wastewaters due to the presence of EPs.

Regarding the risk perception about EPs issues (Fig. 3(a)), most responses of the surveyed experts were classified in the category of "High" with a $40.7 \%$ following by the "Medium" (26.5\%) and the "Very High" (24.8\%) categories. This inform that a $92 \%$ of the 114 experts consider as relevant these problems. In particular, conversion of the ordinal levels, achieved in this question, into numerical scale positions denotes that the average score of this variable (risk perception) is 3.87/5, obtaining therefore the highest value of the variables subset which integrates this section called General aspects (Fig. 3(a)). Respect the adaptation of the treatment systems to meet the requirement of new regulations regarding EPs (Fig. 3(b)), most experts assigned values of "Low" (38.9\%), "Very low" (23.0\%), etc. Likewise, systems preparation achieved 2.26/5.

(a)

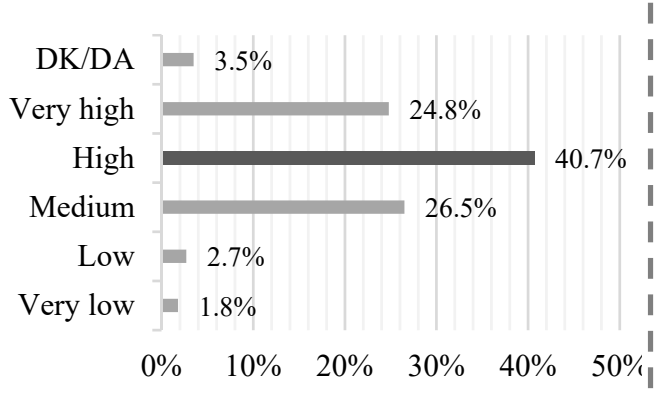

(b)

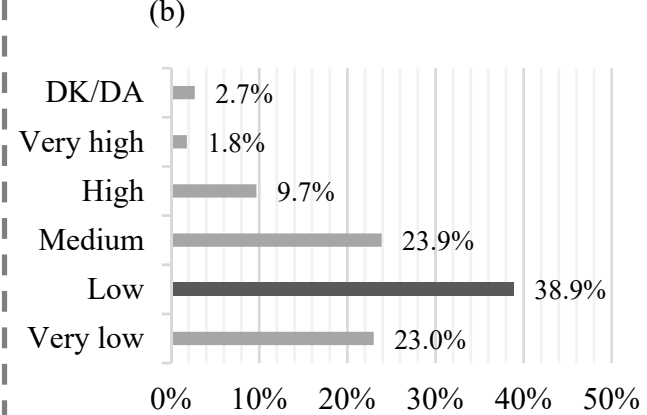

Figure 3: (a) Risk perceived about EPs; (b) Adaptation of the treatment systems.

At the same time, application of new regulations related with EPs issues is considered as "Positive" (31.0\%) and "Very Positive" (23.9\%). Therefore, this variable (impact of new regulations) achieved a great average score (3.55/5, Fig. 4(a)). According with results obtained in the application of new normative, most experts indicated the relevance and needs for new techniques which can determine new, and probably lower, concentrations of EPs fixed by the planned regulations (Fig. 4(b)). In particular, the "Development of analysis techniques" variable acquired an average score of 3.73/5.

The assess related with the cost of new equipment, or certain improvements in the existing equipment, generated rejection between the surveyed experts being the "Regular" and "Negative" categories the most selected (Fig. 5(a)). This variable obtained an average score of 2.89/5. On the other hand, experts estimated improvements of the EPs scientific knowledge as essential being the "Very high" category the most selected with a $30.1 \%$ (Fig. 5(b)). In particular, this variable gained an average score of 3.78/5. 
(a)

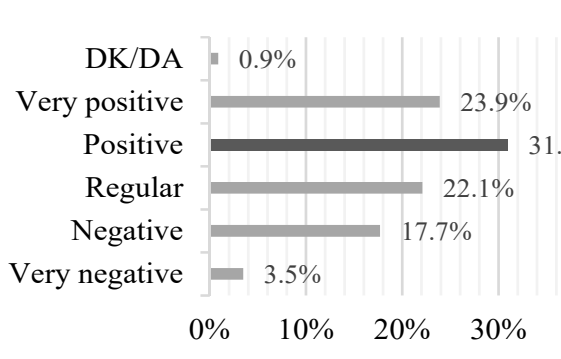

(b)

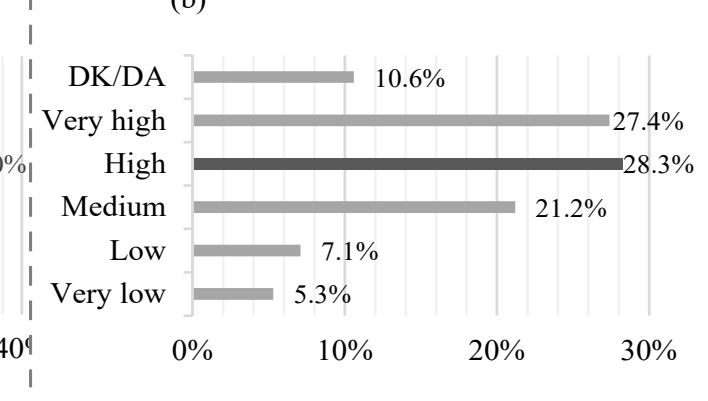

Figure 4: (a) Impact of new regulations; (b) Development of analysis techniques.

(a)

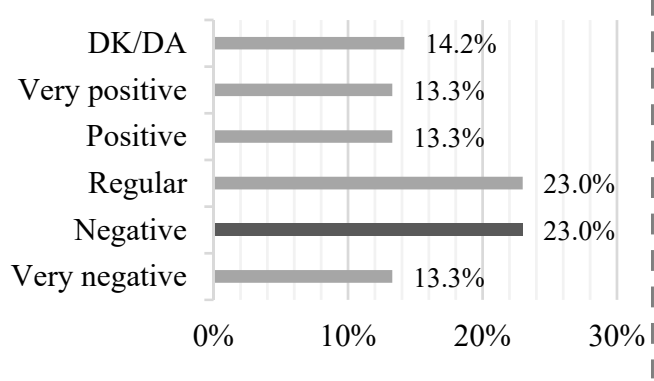

(b)

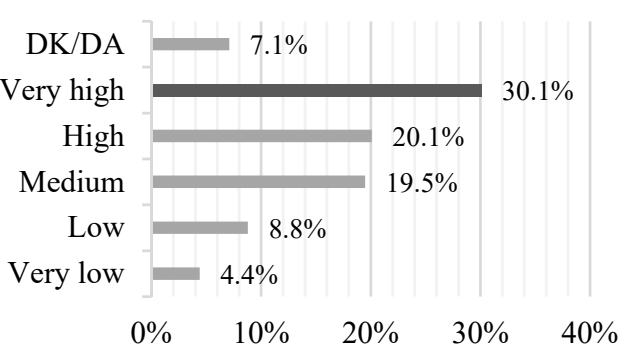

Figure 5: (a) Cost of analysis equipment; (b) Training and scientific knowledge.

\subsection{Technologies}

One of the aims of this sub-section was to assess the perception that the experts have about the effectiveness of the different processes to remove EP: membrane processes (Ultrafiltration and Reverse Osmosis), Advanced Oxidation Processes, Electrochemical Processes and Adsorption. The responses of the surveyed experts are showed in Fig. 6.

Regarding the membrane process Ultrafiltration (Fig. 6(a)), most experts classified the effectiveness of this process to remove EPs in the category "High" (27.4\%) and others in "Very high" (11.5\%). The $24.8 \%$ of the participants classified the effectiveness as "Medium", and only a $18.5 \%$ of them choose the category "Low" (15\%) and "Very low" (3.5\%). This inform that a $63.7 \%$ of the 114 experts consider this technology can efficiently remove EPs from wastewaters. The average score of this variable (effectiveness of Ultrafiltration to remove EPs) into numerical scale is 3.34/5.

With respect to Reverse Osmosis (Fig. 6(b)), most experts classified the effectiveness of this process to remove EPs in the category "High" (31.9\%) and others in "Very high" (23.0\%). The $17.7 \%$ of the participants classified the effectiveness as "Medium", and only a $9.7 \%$ of them choose the category "Low" $(8.8 \%)$ and "Very low" $(0.9 \%)$. This inform that a $72.6 \%$ of the 114 experts consider this technology can efficiently remove EPs from wastewaters. The average score of this variable (effectiveness of Reverse Osmosis to remove 
(a) Ultrafiltration

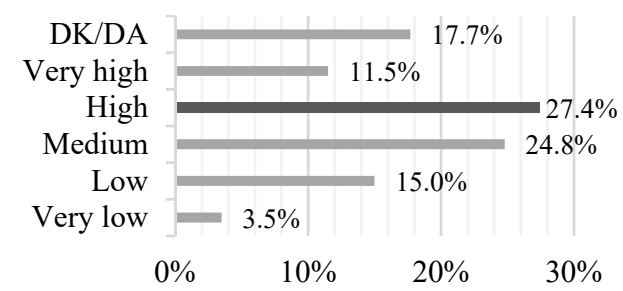

(c) Advanced Oxidation Processes

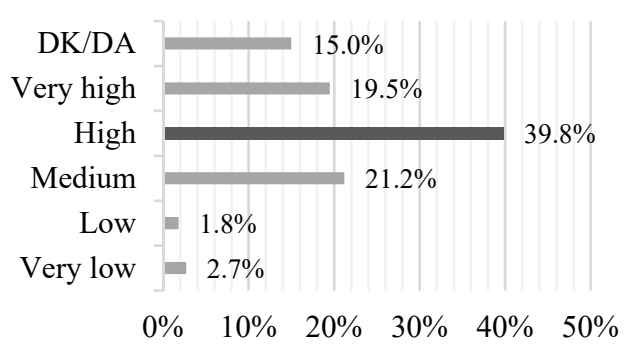

(b) Reverse Osmosis
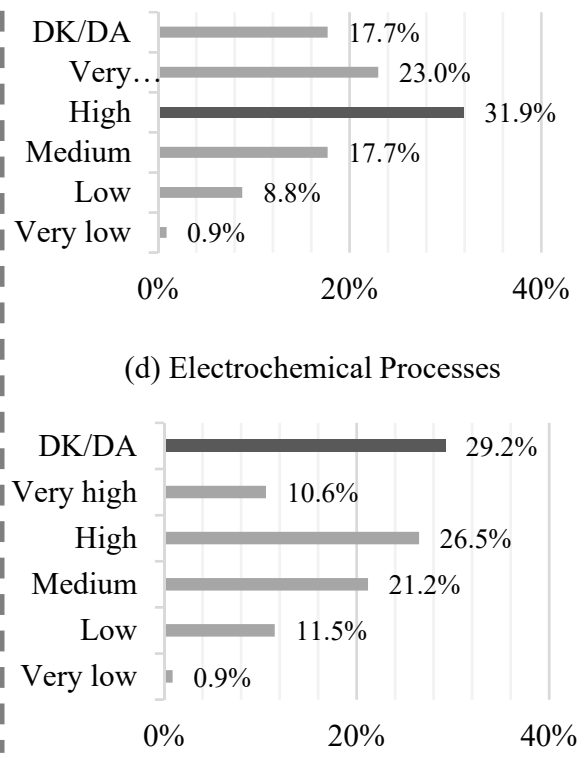

(e) Adsorption

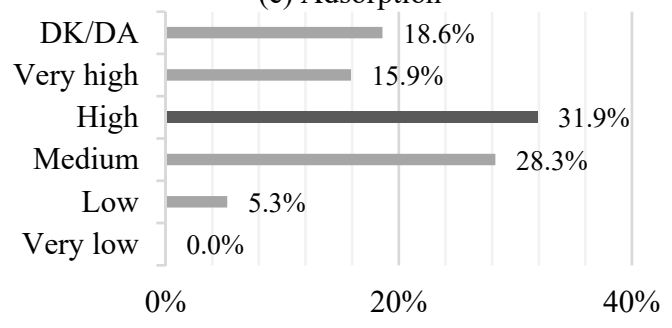

Figure 6: Technologies to remove EPs from wastewaters.

EPs) into numerical scale is 3.82/5. Comparing the average scores for membrane processes, experts considered more efficient the Reverse Osmosis process.

In relation to Advanced Oxidation Processes (Fig. 6(c)), most experts classified the effectiveness of this process to remove EPs in the category "High" (39.8\%) and others in "Very high" (19.5\%). The $22.2 \%$ of the participants classified the effectiveness as "Medium", and only a $4.5 \%$ of them choose the category "Low" (1.8\%) and "Very low" (2.7\%). This inform that the $80.5 \%$ of the 114 experts consider this technology can efficiently remove EPs from wastewaters. The average score of this variable (effectiveness of Advanced Oxidation Processes to remove EPs) into numerical scale is 3.84/5.

Regarding Electrochemical Processes (Fig. 6(d)), most experts classified the effectiveness of this process to remove EPs in the category "High" (26.5\%) and others in "Very high" $(10.6 \%)$. The $21.2 \%$ of the participants classified the effectiveness as "Medium", and only a $12.4 \%$ of them choose the category "Low" $(11.5 \%)$ and "Very low" $(0.9 \%)$. This inform that a $58.3 \%$ of the 114 experts consider this technology can efficiently remove EPs from 
wastewaters. The average score of this variable (effectiveness of Reverse Osmosis to remove EPs) into numerical scale is $3.49 / 5$. It is worth noting that this technology was the less known by the experts $(29.2 \%$ of the responses in category DK/DA).

Concerning Adsorption (Fig. 6(e)), most experts classified the effectiveness of this process to remove EPs in the category "High" $(31.9 \%)$ and others in "Very high" $(15.9 \%)$. The $28.3 \%$ of the participants classified the effectiveness as "Medium", and only a $5.3 \%$ of them choose the category "Low" (5.3\%) and "Very low" $(0.0 \%)$. This inform that a $76.1 \%$ of the 114 experts consider this technology can efficiently remove EPs from wastewaters. The average score of this variable (effectiveness of Adsorption to remove EPs) into numerical scale is $3.72 / 5$.

Considering the opinion of experts (average scores), the processes can be ordered from more to less effectiveness to remove EPs as: Advanced Oxidation Processes, Reverse Osmosis, Adsorption, Electrochemical Processes and Ultrafiltration.

Other aim of this sub-section was to assess the perception that the experts have about the need for the combination of technologies to obtain effluents without EPs. The responses of the surveyed experts are showed in Fig. 7.

Need for technological combination

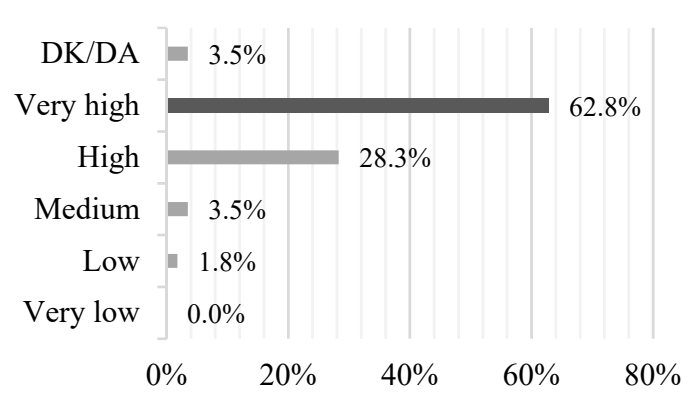

Figure 7: Combination of technologies to obtain effluents without EPs.

As it was previously commented, there were different opinions about the effectiveness of each individual process (Ultrafiltration, Reverse Osmosis, Advanced Oxidation Processes, Electrochemical Processes and Adsorption) to remove EPs from wastewaters. However, it dares highlighting that most experts ( $91.1 \%$ of the 114 experts) agreed on the need to combine those technologies to efficiently remove EPs, as their responses confirmed: "High" (28.3\%) and "Very high" $(62.8 \%)$. Only the $5.3 \%$ of the participants classified this need as "Medium" $(3.5 \%)$, "Low" (1.8\%) and "Very low" $(0.0 \%)$. The average score of this variable (need for technological combination to remove EPs) into numerical scale is $4.58 / 5$.

\subsection{Social, economic and environmental impact of EPs management}

The aim of this sub-section was to analyse the impact that the combination of technologies for the removal of EPs would have on the following social, economic and environmental spheres.

In relation to the impact on public health, the most repeated category was "very positive", with $55.8 \%$ of the answers. This category and the option "positive" combine more than $85 \%$ 
of the total responses. Thus, the average score of this variable is $4.44 / 5$, the highest value of the subset of variables on the impact generated by the elimination of EPs. This data illustrates the strong relationship between EPs and health. The effect of EPs on human health is the main cause of concern for expert users (Fig. 8(a)).

(a)

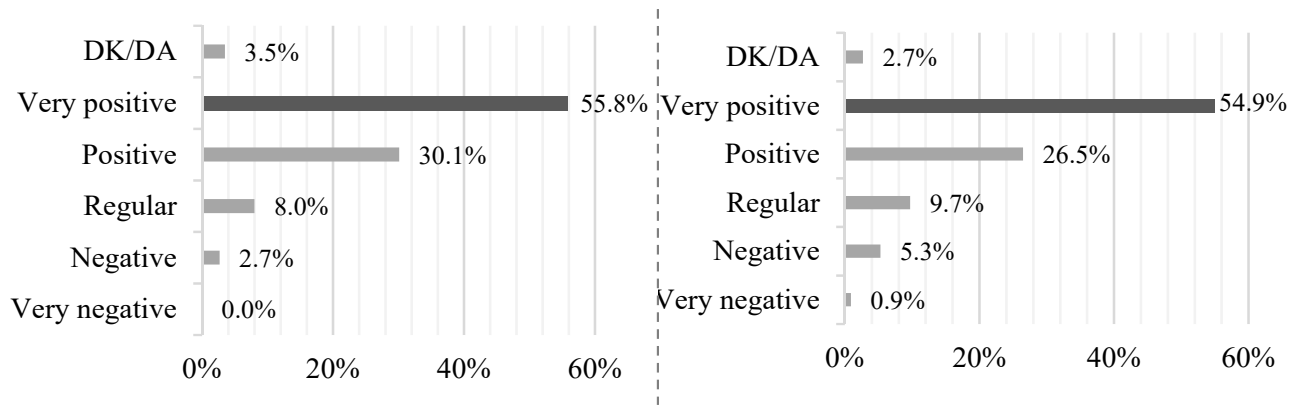

Figure 8: (a) Impact of EPs on public health; (b) Impact of EPs on environmental sustainability.

(a)

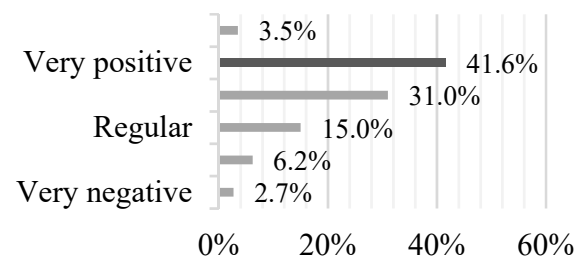

(b)

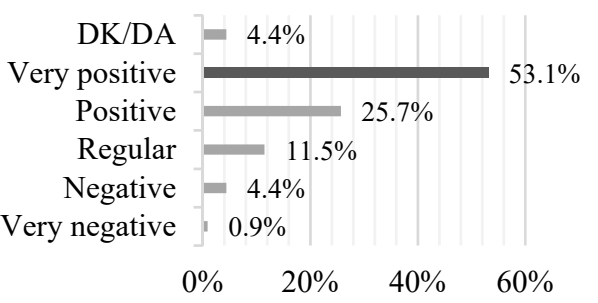

Figure 9: (a) Impact on water resources management; (b) Impact on social trust.

Regarding the impact on environmental sustainability (Fig. 8(b)), the responses are also homogeneous. More than half of the people who responded to the survey considered that the impact would be "very positive." The categories "regular" and "negative" represent residual percentages. The average score of this variable is 4.33/5. A greater control of the discharges, materialized through an adequate elimination of EPs, could generate positive impacts at the environmental level, such as the increase in the quality of the ecological flow of the rivers and their corresponding ecosystem benefits.

On the other hand, in relation to the impact that the elimination of EPs (Fig. 9(a)) would have on the management of water resources, the data are also quite positive. The average score of this variable, however, is the lowest of this sub-set of variables, with a value of 4.06/5. Despite being the lowest average, it exceeds 4 , so it is a positive assessment. The EPs, as has been verified with the data of other variables, are a very important factor to understand 
the assessment and the future of water reuse. Therefore, its elimination could mean an increase in the consumption of reclaimed water (Fig. 9(a)).

In terms of social trust, the data is very similar, although slightly better than the previous variable. The average score is $4.31 / 5$. Therefore, the categories "very positive" and "positive" concentrate almost $80 \%$ of the total responses. The concerns of expert users about the effects of reclaimed water on human health are equivalent to those of citizens in general (March et al. [17]). A EPs-free water could generate greater social trust over non-conventional water resources (water reuse and desalination, Fig. 9(b)).

The second lowest average score of this sub-set of variables was the impact on the laboral market (Fig. 10(a)), with a value of 4.11/5. In this case, the most repeated category is "positive", with $40.7 \%$ of the answers. This category and the option "very positive" concentrate more than $75 \%$ of the answers. The overall assessment of this variable is significantly positive. Technological advances and investment in projects related to the elimination of EPs could stimulate some economic sectors and facilitate the financing of the scientific staff of some research centers.

(a)

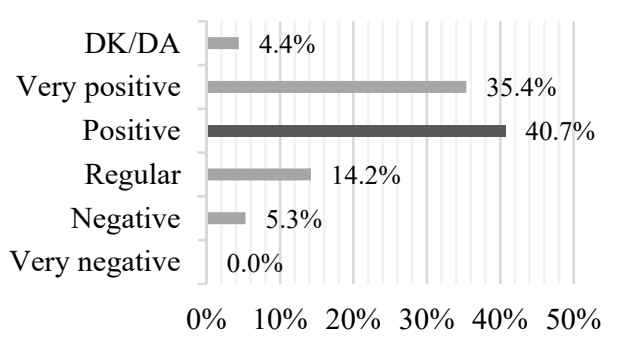

(b)

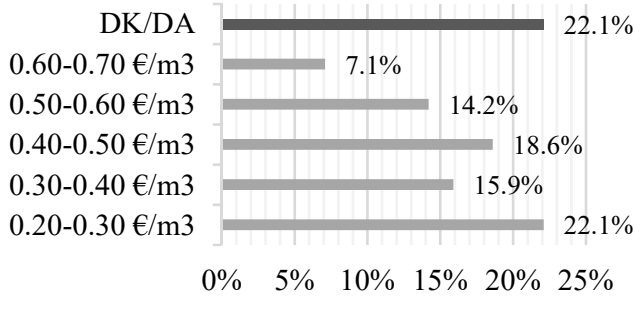

Figure 10: (a) Impact on laboral market; (b) Acceptable price.

An economic aspect that is interesting to analyse is the acceptable price for EPs-free water (Fig. 10(b)). It is worth noting the high level of ignorance about the price of water. $22.1 \%$ of people did not know the price. This option is the most repeated category. Secondly, the acceptable price of EPs-free water that users indicated is "very low". $22.1 \%$ of people considered that the most acceptable price range is $" 0.20-0.30 € / \mathrm{m}^{3 "}$, the lowest level proposed. This information is consistent with the data of the variable on the willingness of users to pay more for EPs-free water (Fig. 11). $42.5 \%$ of users indicated they were willing to assume an increase in the price as long as it was moderate. About $18 \%$ of the experts indicated that they are willing to assume a higher price if the increase is minimal.

\section{CONCLUSIONS}

Main conclusions of the present study are listed below:

- To sum up, the section called General Aspects presented main results of the study related with the risk perception, adaptation systems, impact of new regulations, development of analysis techniques, cost of analysis equipment, training and scientific knowledge. It should be noted that the risk perception and the improvement of the scientific knowledge were the variables considered the most relevant of this section. Obviously, these are variables closely related since the high-risk perception can be considered the reason by experts estimated improvement of the scientific knowledge as essential. 


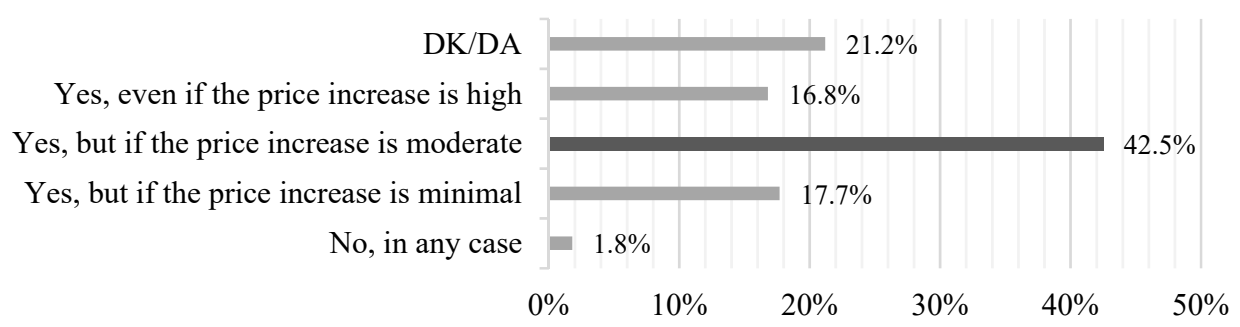

Figure 11: Propension to pay more.

- Considering the opinion of experts (average scores), the processes can be ordered from more to less effectiveness to remove EPs as: Advanced Oxidation Processes, Reverse Osmosis, Adsorption, Electrochemical Processes and Ultrafiltration. It dares saying that Electrochemical Processes was the less known technology by the experts.

- It is worth noting that most experts agreed on the need to combine these technologies to efficiently remove EPs from wastewaters.

- In general, users consider that the elimination of EPs can stimulate positive impacts at a social, economic and environmental level, highlighting the perception of impact in the field of public health. The effect of EPs on human health could be considered the main concern of users.

- Although experts recognize many benefits from the elimination of EPs, they are not willing to assume a significant increase in costs. There is a disproportionate relationship between concerns, expectations and willingness to adapt to new economic realities. This constitutes a factor of uncertainty and vulnerability that affects the current wastewater management and treatment systems.

\section{ACKNOWLEDGEMENTS}

This project was produced under the co-finance of the European financial instrument for the Environment (LIFE) programme during the implementation of the project "LIFE EMPORE" (LIFE15 ENV/ES/000598). Pablo Aznar-Crespo and Antonio Jodar-Abellan acknowledge financial support received from the Spanish FPU scholarship for the training of university teachers. In the same way, this work has been conducted within the Cátedra del Agua of the University of Alicante (https://catedradelaguaua.org/). Finally, the authors acknowledge the reviewers of the manuscript whose comments contributed greatly to improve this paper.

\section{REFERENCES}

[1] Directive 2000/60/EC of the European Parliament and of the Council of 23 October 2000, Establishing a framework for Community action in the field of water policy.

[2] Directive 2013/39/EU of the European Parliament and of the Council, of 12 August 2013, Amending Directives 2000/60/EC and 2008/105/EC as regards priority substances in the field of water policy.

[3] Directive 91/271/EEC. Council Directive of 21 May 1991, Concerning urban waste water treatment. 
[4] Directive 98/15/EC. Commission Directive 98/15/EC of 27 February 1998, Amending Council Directive 91/271/EEC with respect to certain requirements established in Annex I thereof (Text with EEA relevance).

[5] BIO Deloitte, Optimising water reuse in the EU. Final report for the European Commission (DG ENV), Part I. In collaboration with ICF and Cranfield University, 2015.

[6] Confederación Hidrográfica del Segura (CHS), Plan Hidrológico de la Demarcación del Segura, Memoria, Ministry of Agriculture and Environment, p. 1-762, 2015.

[7] Gomariz-Castillo, F., Alonso-Sarria, F. \& Cabezas-Calvo-Rubio, F., Calibration and spatial modelling of daily ET0 in semiarid areas using Hargreaves equation. Earth Science Informatics, 11(3), pp. 325-340, 2017.

[8] Ruíz-Álvarez, M., Gomariz-Castillo, F. \& Alonso, F., Análisis espacio-temporal de los cambios previstos en la evapotranspiración de referencia durante el siglo XXI en la Demarcación Hidrográfica del Segura (España) a partir de los modelos MPEH5 y MPEH5C. Revista de Geografía Norte Grande, 71, pp. 35-58, 2018.

[9] Albaladejo-García, J.A., Martínez-Paz, J.M. \& Colino, J., Evaluación financiera de la viabilidad del uso de agua desalada en la agricultura de invernadero del Campo de Níjar (Almería, España). Información técnica económica agraria, 114(4), pp. 398414. 2018.

[10] Grindlay-Moreno, A.L. \& Lizárraga-Mollinedo, C., Regadío y territorio en la Región de Murcia: evolución y perspectivas de futuro. Ciudad y Territorio, 172, pp. 281-298, 2012.

[11] Custodio, E. et al., Groundwater intensive use and mining in south-eastern peninsular Spain: Hydrogeological, economic and social aspects. Science of the Total Environment, 559(1), pp. 302-316, 2016.

[12] Melgarejo-Moreno, J., López-Ortiz, M.I. \& Fernández-Aracil, P., Water distribution management in South-East Spain: A guaranteed system in a context of scarce resources. Science of the Total Environment, 648, pp. 1384-1393, 2019.

[13] Molina-Giménez, A. \& Melgarejo-Moreno, J., Water policy in Spain: seeking a balance between transfers, desalination and wastewater reuse. International Journal of Water Resources Development, 32(5), pp. 781-798, 2015.

[14] Zarzo, D. \& Prats, D., Desalination and energy consumption. What can we expect in the near future? Desalination. 427, pp. 1-9, 2018.

[15] Prats-Rico, D., Reuse of Purified Regenerated Water Worldwide: Analyzes and Projections. Water and landscape. 8, pp. 10-21, 2016.

[16] SPSS code: Statistical Product and Service Solutions, www.spss.com.hk/. Accessed on: 22 Nov. 2018.

[17] March, H., Hernández, M. \& Saurí, D., Percepción de recursos convencionales y no convencionales en áreas sujetas a estrés hídrico: el caso de Alicante. Revista de Geografía Norte Grande, 60, pp. 153-172, 2015. 